\title{
Por uma reconfiguração das relações entre cena teatral e minoritarismo
}

\section{Towards a reconfiguration of the relations between the theatrical scene and minoritarianism}

Alberto Ferreira da Rocha Junior ${ }^{1}$ 


\section{Resumo}

O foco deste artigo é a discussão sobre o que chamamos de minoritarismo, entendido enquanto formação de uma concepção identitária que favorece a reiteração de uma lógica essencializante na luta pelos direitos humanos. Nesse sentido, não propomos a análise de nenhuma obra em específico, mas uma reflexão que, a partir de alguns exemplos da atualidade, possa problematizar certos aspectos da luta pelos direitos humanos em sua relação com a produção cultural e artística e vislumbrar se não saídas, ao menos horizontes de transformação.

Palavras-chave: Teatro brasileiro; minorias; diversidade sexual

\section{Abstract}

The focus of this article is the discussion about what we call minoritarianism, understood as the formation of a conception of identity that favors the reiteration of an essentializing logic in the struggle for human rights. We do not propose the analysis of any specific theatrical work, but rather a reflection that, based on some current examples, may problematize certain aspects of the struggle for human rights in relation to cultural and artistic production and to open horizons for transformation.

Keywords: Brazilian theatre; minorities; sexual diversity

E-ISSN: 2358.6958

1 Prof. Dr. Universidade Federal de São João del-Rei tibaji.alberto@gmail.com 
Este artigo é produto da pesquisa Diversidade sexual e teatro no Brasil: visibilidade, minoritarismo e representação, iniciada em 2017 e que dá prosseguimento a algumas questões surgidas durante a pesquisa anterior, intitulada Araci: teatro, contemporaneidade e extensão universitária. ${ }^{2}$ São questões candentes na atualidade brasileira - e talvez mesmo em termos globais - tanto do ponto de vista da militância dos direitos humanos, e no nosso caso especificamente da militância em prol da defesa dos direitos da população LGBT, ${ }^{3}$ quanto do ponto de vista dos estudos acadêmicos sobre o tema. Fazem parte também dessa discussão produtos das mais variadas expressões artísticas e culturais, como obras de artes visuais, espetáculos teatrais, telenovelas e programas de entretenimento em geral.

O foco deste artigo é a discussão sobre o que chamamos de minoritarismo, entendido enquanto formação de uma concepção identitária que favorece a reiteração de uma lógica essencializante na luta pelos direitos humanos.

Nesse sentido, não propomos a análise de nenhuma obra teatral em específico, mas uma reflexão que, a partir de alguns exemplos da atualidade, possa problematizar certos aspectos da luta pelos direitos humanos em sua relação com a produção cultural e artística e vislumbrar se não saídas, ao menos horizontes de transformação.

\section{Minoritarismo}

Eve Kosofsky Sedgwick em seu livro Epistemologia do armário ${ }^{4}$ - que aguarda publicação em português - aponta um impasse fundamental e ainda pouco discutido, apesar de a primeira edição em inglês ter sido publicada em 1990: a luta pelos direitos humanos caminha sobre o tensionamento entre um ponto de vista universalizante [universalizing], quando afirmamos que todos os seres humanos são iguais e devem possuir direitos básicos iguais, e um ponto de vista "minoritarizante" [minoritizing], quando afirmamos a existência de identidades específicas que devem ser respeitadas: mulheres, lésbicas, gays, negras/os etc.

Em sua reflexão, a autora - apesar de se colocar mais próximo das perspectivas facilmente identificáveis como "construtivistas", em oposição àquelas identificáveis como "essencialistas" - busca assegurar que seu objetivo não é desconstruir a visão minoritarizante para inviabilizar as ações de garantias e de conquistas de direitos humanos e civis para a população LGBT. Essa seria provavelmente alternativa que, em última análise, denotaria incompreensão do fundamento da questão discutida. Eve Kosofksy Sedgwick não vislumbra nenhuma possibilidade de deslocar-se para um lugar exterior ao impasse no qual estamos todas/todos inseridas/os: "[o] objetivo deste livro é não adjudicar entre os dois polos de nenhuma dessas contradições, porque, se seu argumento está correto, não há fundamento epistemológico existente a partir do

\footnotetext{
2 O referido projeto teve financiamento do Edital PROEXTE/MEC 2014, do Edital 07/2013, Apoio a Projetos de Extensão em interface com a Pesquisa da FAPEMIG, e do Edital 03/2014 Programa Pesquisador Mineiro da FAPEMIG.

3 Vários grupos vêm lutando para obter visibilidade como intersexuais, assexuais, não binários, queer etc. Optamos por usar a sigla reconhecida por órgãos públicos brasileiros em geral.

4 A editora Autêntica já anunciou a preparação do livro de Sedgwick para breve (Cf. Spargo, 2017, p.52). Até o momento o que há publicado em português é o primeiro capítulo do livro, do qual herda o título (cf. Sedgwick, 2008).
} 
qual poderíamos fazê-lo" (Sedgwick, 2008, p.2). ${ }^{5}$ Essa hipótese formulada pela autora é fundamental para o desenvolvimento de nossa reflexão. Ela se relaciona também com o posicionamento de Judith Butler (2015) em Problemas de gênero: feminismo e subversão da identidade.

Em outras ocasiões já manifestamos nossa insatisfação em relação à tradução do título da obra de Butler, que reifica a desconstrução da noção de gênero, colocando no plural a palavra trouble. A tradução do título parece-nos trazer uma expectativa de exibição de determinada ou indeterminada quantidade de problemas de gênero existentes, quando, em inglês, a palavra está no singular. Se conferirmos o final do primeiro capítulo em inglês, podemos observar que a autora usa a expressão gender trouble:

This text continues, then, as an effort to think through the possibility of sub-
verting and displacing those naturalized and reified notions of gender that su-
pport masculine hegemony and heterosexist power, to make gender trouble, not
through the strategies that figure a utopian beyond, but through the mobilization,
subversive confusion, and proliferation of precisely those constitutive categories
that seek to keep gender in its place by posturing as the foundational illusions of
identity. (Butler, 2008, p.33-34)

A tradução em português, em vez de combater as "noções reificadas de gênero", reforça tal reificação no momento em que propõe que o esforço do livro de Judith Butler seria criar "problemas de gênero", quando a expressão em inglês - make gender trouble - parece apontar mais para uma problematização da noção de gênero. Eis como foi publicado o mesmo trecho em português:

O texto continuará, então, como um esforço de refletir a possibilidade de subverter e deslocar as noções naturalizadas e reificadas do gênero que dão suporte à hegemonia masculina e ao poder heterossexista, para criar problemas de gênero não por meio de estratégias que representem um além utópico, mas da mobilização, da confusão subversiva e da proliferação precisamente daquelas categorias constitutivas que buscam manter o gênero em seu lugar, a posar como ilusões fundadoras da identidade. (Butler, 2015, p.70) ${ }^{6}$

É fundamental observar que no texto de Butler, aparece uma crítica ao "além utópico", ou seja, a crítica que se pode fazer à noção de gênero não se deve orientar por um "além utópico" no qual estaríamos livres das imposições da noção de gênero; a crítica deve se fazer por meio de uma "confusão subversiva" e de uma "proliferação", remetendo-nos, portanto, a uma ideia de indecidibilidade e de instabilidade do terreno no qual construímos nossas identidades.

Tanto Butler quanto Sedgwick, portanto, produzem uma crítica à noção de identidade fundamental para a estrutura do pensamento e da produção do conhecimento na sociedade ocidental. Sedgwick, justamente para reafirmar sua intenção de não abandonar o impasse entre a compreensão minoritarizante e a compreensão universalizante, afirma:

\footnotetext{
5 "The purpose of this book is not to adjudicate between the two poles of either of these contradictions, for, if its argument is right, no epistemological grounding now exists from which to do so" (Tradução nossa).

6 É significativo que em francês o livro tenha como título Trouble dans le genre; pour un féminisme de la subversion.
} 
Repetidas vezes senti, enquanto escrevia o livro, que, apesar de minhas próprias identificações, intuições, circunstâncias, limitações e talentos terem talvez conduzido suas interpretações no sentido de privilegiar certas compreensões da escolha sexual, a construtivista em detrimento da essencialista, a universalizante em detrimento da minoritarizante, a gênero-transitiva da gênero-separatista, o espaço de permissão para este trabalho e a profundidade da paisagem intelectual para a qual ele poderia trazer uma contribuição devem tudo à riqueza do pensamento gay essencialista, minoritarizante e separatista e à luta sendo travada. (Sedgwick, 2008, p.13) ${ }^{7}$

Assim, ainda que seja inegável a importância da compreensão minoritarizante, que delimita e identifica um determinado grupo social como homossexual, por exemplo, e ainda que essa compreensão seja efetivamente imprescindível para a garantia e conquista de direitos humanos e civis, é indispensável perceber que a compreensão minoritarizante está assentada sobre princípios que, teoricamente, precisam ser criticados.

\section{Polemistas globais?}

A história recente do espetáculo teatral no Brasil vem solicitando de artistas e de pesquisadoras/es que se debrucem sobre a relação entre minoritarismo e teatro, e ainda que não seja esse nosso objeto específico de análise, vamos abordar algumas discussões sobre esse aspecto. Essa relação vem exigindo uma discussão sobre negritude e cena. Reiteradas vezes temos visto debates e conflitos envolvendo artistas, comunidade negra e militantes. A título de exemplo, lembramos dois momentos da história do espetáculo teatral em São Paulo. O primeiro deles ocorrido em 2015, quando a Companhia Os Fofos Encenam suspendeu a apresentação do espetáculo A mulher do trem, após acusações de que o espetáculo apresentava conteúdo racista por utilizar a técnica do black face para caracterizar duas personagens negras da peça. O segundo momento ocorreu em 2016, com a montagem de Exhibition B, do artista sul-africano Brett Bailey. Após protestos e acusações, que afirmavam que o espetáculo apresentava conteúdo racista, a vinda do espetáculo foi cancelada. No caso de Exhibition B, o espetáculo já havia sido cancelado em 2014 em Londres, também após protestos e acusações de que o espetáculo apresentava conteúdo racista, mesmo depois de ter sido apresentado em festivais na Europa continental, o que nos obriga a perceber que se trata de uma questão mundializada e não apenas restrita à realidade brasileira.

A armadilha, em todos os casos, está, do ponto de vista da reflexão acadêmica, em tentar de imediato tomar partido. A encenação de situações de tortura e de situações humilhantes às quais certos grupos minoritários foram e são historicamente submetidos é necessariamente preconceituosa? Deve-se banir da cena teatral esse tipo de espetáculo? Esses protestos também ocorrem em relação a filmes que relatam essas mesmas situações? Todo espetáculo que exibir situações humilhantes deve ser impedido de vir à cena?

\footnotetext{
Over and over I have felt in writing the book that, however my own identifications, intuitions, circumstances, limitations, and talents may have led its interpretations to privilege constructivist over essentialist, universalizing over minoritizing, and gender-transitive over gender separatist understandings of sexual choice, nevertheless the space of permission for this work and the depth of the intellectual landscape in which it might have a contribution to make owe everything to the wealth of essentialist, minoritizing, and separatist gay thought and struggle also in progress" (Tradução nossa).
} 
Aqui voltamos à questão da diversidade sexual. ${ }^{8}$ Recentemente episódios a ela relativos geraram comentários, notícias, processos judiciais e discussões públicas e ainda ecoam nas mídias sociais. A atriz Renata Carvalho teve cancelada a apresentação de seu espetáculo $O$ evangelho segundo Jesus, rainha do céu no Sesc-Jundiaí porque "figuras religiosas não podem ser expostas ao ridículo". ${ }^{9} \mathrm{~A}$ ideia de exposição ao ridículo está fundamentada justamente na ideia de que uma travesti - Renata Carvalho - seria um ser inferior e não poderia desempenhar o papel de Jesus Cristo. Voltamos à pergunta: todo espetáculo que exibir situações humilhantes deve ser impedido de vir à cena? Como e quem pode determinar se a exibição da imagem de Jesus Cristo desempenhada por uma travesti se constitui como humilhação à fé cristã? O que o juiz que proibiu a apresentação do espetáculo da artista Renata Carvalho diria de Exhibit $B$ ? $O$ que os militantes que protestaram contra a Exhibit $B$ diriam de $O$ evangelho segundo Jesus, rainha do céu? A minoria negra deve ser protegida de humilhações e os conservadores cristãos não devem ser respeitados em suas imagens de fé? Toda transfiguração de um objeto de fé é sinônimo de desrespeito a determinada crença religiosa?

Em meio a tanto alvoroço e tanta circulação de opiniões nas mídias sociais, "esse grande canal de incontinência", como observou Álvaro Costa e Silva (2017), é preciso refletir sobre o discurso que sustenta os enunciados, e, nesse sentido, vale a pena rememorar a obra marcante de Roberto Ventura (1991), Estilo tropical: história cultural e polêmicas literárias no Brasil. Certamente, as polêmicas literárias do século XIX no Brasil não pertencem à situação das polêmicas do nosso século XXI, contudo, alguns aspectos da obra do crítico brasileiro podem nos ajudar a compreender o momento atual.

\footnotetext{
Nas polêmicas do século XIX, o debate se desenrola sem que haja objeto determinado, ou se defina um assunto ou questão em pauta. Fala-se sobre tudo e sobre todos. Digressões se seguem a longas citações e demonstrações de erudição. O tema inicial, que desencadeou a polêmica, se torna pretexto para que dois ou mais interlocutores exibam a sua retórica e erudição. Se a polêmica se dá sem objeto, pode-se supor que a polarização entre os debatedores se dê a partir de diferenças culturais, científicas ou políticas, o que tampouco se verifica. Os polemistas se opõem sem que haja posições que expliquem o porquê do conflito. Muitos dos erros que o polemista aponta no seu interlocutor se fazem presentes tanto neste quanto naquele. (Ventura, 1991, p.146)
}

Talvez uma das grandes diferenças entre as polêmicas do século XIX e as polêmicas do século XXI seja a atual inexistência de uma tentativa de demonstrar erudição. Não há lugar para isso nas polêmicas atuais. Pode-se, agora, demonstrar estar 'em dia' com as polêmicas: citar uma lista de casos que a/o autor/a julga pertinentes para a discussão, com variedade geográfica e temporal significativa. Mas os erros que um polemista aponta em seu interlocutor se fazem presentes também no autor das críticas. Essa já nos parece uma característica em comum entre as duas épocas.

\footnotetext{
8 Neste artigo abrangemos nessa expressão a diversidade de orientações sexuais - incluindo aqui a assexualidade -, a diversidade de gênero e de configurações corporais e genitais. Essa confusão de questões aparentemente distintas faz parte da própria discussão e está cada vez mais presente nas letras que fazem parte da sigla que vem sendo utilizada para se referir à questão. Vale lembrar rapidamente o caminho que vai de GLS, passa por GLBT, LGBT e chega a LGBTQIA+ e outras variantes.

9 Em várias ocasiões a atriz já enfrentou esse tipo de proibição.
} 
Outro aspecto fundamental, apontado por Ventura, está presente nas atuais polêmicas: a sensação de impossibilidade de pronunciar um veredicto: "[o] processo de julgamento não se completava, porém, nesses debates, permanecendo sempre em aberto, pois o 'júri' de leitores não se constitui como instância habilitada a proferir um veredicto final e a declarar o encerramento da contenda" (Ventura, 1991, p.149). De certo modo, pode-se explicar essa impossibilidade pelo próprio veículo da polêmica, acentuando-se no século XXI pela proliferação de redes e de mídias jornalísticas e, sobretudo, sociais. Entretanto, no século XXI, a vivência do que chamaremos aqui de 'relativismo de valores' acentua essa indecidibilidade da polêmica. Sobre isso, discorreremos mais adiante.

Por fim, salientamos a ideia de que há, a partir do fim do século XIX, ênfase na formação de distinções ideológicas entre os contendores: "[a]pesar do predomínio de semelhanças, tais polêmicas mostram as tentativas de se formarem distinções teóricas e políticas, como na disputa entre evolucionistas de formação liberal, positivistas de tendência autocrática e anarquistas e socialistas" (Ventura, 1991, p.152). Isso também está presente nas polêmicas atuais.

O que vemos na mídia, a partir dos casos aqui citados, é a repercussão de tentativas, e frequentemente de vitórias, de censuras a exibições de espetáculos e exposições, mas não discussões aprofundadas sobre o assunto. Ainda que se argumente que jornais e mídias sociais não são o espaço apropriado para debates de questões complexas, há que se levar em consideração que ao menos os comentários deveriam ser justificados e deveriam expressar opiniões de pessoas que tenham tido contato com o objeto sobre o qual se discute. Não é isso, no entanto, o que ocorre, o que nos leva efetivamente a pensar na ideia de que a polêmica, antes de ser um debate sobre tema da atualidade, é uma exibição de força e poder, que visa à censura, ou seja, visa proibir que a população tenha contato com um produto que é considerado por um determinado grupo social - ou indivíduo - nocivo ou ofensivo à sociedade como um todo ou ao grupo social em questão. Dois bons exemplos podem corroborar nesse sentido.

O primeiro aparece em matéria da Folha de S. Paulo, assinada por Gustavo Fioratti. $O$ autor descreve de modo sucinto a polêmica em torno de Exhibit $B$, com várias idas e vindas, suposições e manifestações públicas. Depois de várias tentativas de negociação entre várias partes, decide-se finalmente, segundo o autor, pelo cancelamento da apresentação da obra. Porém, não apenas a obra deve ser impedida de vir a público, mas deve-se garantir a vitória de um grupo sobre o outro:

O resultado foi comemorado entre ativistas, que contestam a versão da MITsp, publicada pela Folha no último dia 2. "Saiu uma reportagem mentirosa informando que o espetáculo foi cancelado por falta de verba, quando na verdade o espetáculo já estava sendo ensaiado", diz texto publicado pela Frente Negra de Erradicação do Racismo em sua página no Facebook. Procurado pela reportagem, o grupo não se pronunciou.

Segundo o texto, Exhibit $\mathrm{B}$ foi cancelado "devido à pressão da população negra brasileira, que não viu coerência em um espetáculo que reproduzia as formas de tortura sofridas pelos seus ancestrais negros escravizados nesse país" (Fioratti, 2016, grifos nossos) 
É possível perceber, portanto, que não é suficiente a obtenção do objetivo desejado, mas acima de tudo é necessária a afirmação da superioridade do poder de um grupo sobre o outro.

O segundo exemplo está em matéria do periódico inglês The Guardian: "Seu abandono foi saudado como uma vitória por ativistas que reivindicaram 20 mil assinaturas em uma petição de protesto contra o que chamavam de 'racismo cúmplice'"10 (Muir, 2014, grifo nosso).

Assim, reiteram-se a importância do resultado da ação militante e o poder do grupo que impediu a realização do espetáculo. Nos dois casos, é também imprescindível lembrar, os grupos militantes obtêm êxito à revelia das/dos artistas negras/os que defenderam seu direito de participar do espetáculo.

Ainda que de modo estapafúrdio e inábil, ${ }^{11}$ artigo publicado por Luiz Felipe Pondé na Folha de S. Paulo de 23 de outubro de 2017 traz para a discussão um ponto fundamental: não seria o politicamente correto uma forma de censura também? Pondé argumenta que

[a] esquerda tem espancado a liberdade de expressão há anos com suas intervenções em nome de um mundo melhor. Não tem nenhuma moral pra reclamar da "nova censura" praticada pela direita, depois dela, esquerda, ter exercido tanto sua "velha censura" politicamente correta. ${ }^{12}$

Se desconsiderarmos o tom do artigo, podemos perceber a pertinência do questionamento. Ainda que o colunista não cite o exemplo dos espetáculos impedidos de se apresentar pelo fato de ser considerados racistas, seria cabível trazê-los para a discussão. Trata-se da característica apontada por Ventura: aquilo que o polemista critica em seu interlocutor é também uma característica sua. Pondé, em seu texto, termina por apontar esse paradoxo.

Deixando a polêmica de lado, o que se observa é, em princípio, um conflito insolúvel: desde as reflexões lançadas por Kant, no final do século XVIII, em Crítica da faculdade de julgar, mais especificamente em "Analítica do belo", a arte vem sendo entendida, enquanto arte, a partir da noção de desinteresse - científico, moral, material -, o que se denominou mais popularmente arte pela arte. ${ }^{13} \mathrm{O}$ que se observou, contudo, a partir do século $X X$, com as discussões sobre discurso e poder, foi que a arte não pode mais se desvincular de modo absoluto da esfera ética. O problema que se coloca, portanto, é: como estabelecer limites éticos para as manifestações artísticas e culturais? E, finalmente, quem deve e pode decidir sobre esses limites?

Sendo assim, nossa discussão precisa migrar do terreno da especulação mili-

\footnotetext{
10 Its abandonment was hailed as a victory by campaigners who claimed 20,000 signatures on a protest petition against what they called 'complicit racism (Tradução nossa).

${ }^{11}$ O próprio título do artigo já mostra certa inabilidade - e talvez animosidade - na elaboração do texto: "Jesus transexual qualquer um faz. Que tal uma peça de Maomé transexual?" A repercussão da peça e os problemas que a equipe de criação vem enfrentando com a proibição de suas apresentações são evidências de que não é qualquer um/a que pode fazer um Jesus transexual. Só pode fazer um espetáculo desses quem tiver disposição para enfrentar a fúria das publicações nas mídias sociais e de notícias. Seria interessante observar qual seria a reação dos mesmos grupos sociais diante de um Jesus desempenhado por um homem trans ou por alguma atriz brasileira cis, que tenha visibilidade midiática.

12 Mantivemos o texto exatamente como foi publicado no periódico - apesar de não seguir as normas da gramática da língua portuguesa - porque acreditamos que, desse modo, o tom coloquial e de animosidade fica mais evidenciado.

13 Trata-se evidentemente da noção kantiana de desinteresse.
} 
tante dos direitos humanos em geral para a especulação teórica sobre as relações entre teatro e ética; é preciso migrar da polêmica das mídias para a crítica da noção de autonomia da arte..$^{14}$

\section{Militante, portanto, justiceiro?}

É importante destacar aqui outro aspecto da polêmica: de certo modo, os grupos de militantes vinculados a identidades minoritárias parecem exacerbar um sistema no qual trabalham ao menos três funções: a do opressor, a da vítima e a do justiceiro. ${ }^{15}$

Denominamos aqui justiceiro aquele indivíduo que, ao identificar característica opressora em qualquer prática discursiva, atitude ou comportamento, imediatamente toma como opressora a pessoa que realizou tal ação, vedando qualquer possibilidade de incongruência entre a expressão do sujeito, sua intenção e sua própria subjetividade. Em outras palavras, a pessoa é imediatamente percebida em sua totalidade como sujeito opressor, sem nenhum tipo de fresta que permita contradição. Mais ainda, o justiceiro não pode aceitar nenhuma outra possibilidade de leitura que não a sua. Tanto no caso da militância negra que impede a realização de Exhibit $B$ quanto no caso dos grupos conservadores cristãos que impedem a realização de $O$ evangelho segundo Jesus, rainha do céu, a sociedade não pode discutir sobre o sentido do espetáculo, porque ele nem mesmo deve ser apresentado, devendo todo o corpo social seguir, sem a obra, os critérios de um grupo específico.

Da parte desse comportamento justiceiro há também uma dificuldade em compreender que não se deve combater a hegemonia da fala por meio da censura à fala. É cada vez mais recorrente nas discussões que envolvem identidades minoritarizantes a exigência, por parte desse comportamento justiceiro, do silêncio [e até que ponto esse silenciamento é não apenas censura, mas autoritarismo?] de todo indivíduo que não faça parte do grupo minoritário quando qualquer aspecto relativo a sua identidade está em jogo.

Assim, se você não é uma travesti, você não pode discutir nenhum aspecto que esteja relacionado à essa minoria. Se você não é lésbica, você não pode discutir nenhum aspecto relacionado a essa minoria; se você não é transexual, você não pode discutir nenhum aspecto relacionado a essa minoria. Em suma, parte-se do pressuposto de que somente quem pertence àquela minoria detém a verdade a seu respeito, sua realidade e sua identidade. Essa afirmação parte do seguinte pressuposto: o sujeito é o proprietário exclusivo de sua verdade, desconsiderando, no mínimo, os questionamentos que o pensamento marxista e as teorias freudianas, por exemplo, trouxeram à ideia de autonomia do sujeito iluminista e burguês. Novamente, o que vemos é a impossibilidade da existência de leituras divergentes.

\footnotetext{
14 Partimos do pressuposto de que não é mais possível, em termos históricos e sociais, construir uma reflexão sobre o teatro - e a arte - na contemporaneidade que esteja fundamentada na noção de autonomia da arte. Sobre o assunto, permitimo-nos indicar nosso artigo publicado no periódico ArtCultura (Tibaji, 2000).

15 Essas expressões são tomadas livremente de empréstimo aos estudos de constelações familiares, desenvolvidos por Bert Hellinger. Agradeço a Maria Cláudia Canto Cabral as longas discussões sobre o assunto.
} 
E aqui retornamos à questão da indecidibilidade da polêmica: a ideia de relatividade tornou-se tão natural, que sustenta qualquer recusa de leitura divergente. Para evitar a crítica, basta dizer: "esse é o seu modo de pensar, eu penso de modo diferente". E necessariamente a/o interlocutor/a deve aceitar esse argumento, sob pena de estar desrespeitando a/o locutor/a. ${ }^{16}$ Vale retomar aqui Teoria e valor cultural, de Steven Connor (1994, p. 17), em que o autor afirma: "[o] valor é inescapável". Ao desenvolver seu argumento, Connor aponta para uma espécie de aporia da contemporaneidade: se tudo é relativo, a frase tudo é relativo deveria ser relativa, e, para ser relativa, seria preciso que algo fosse absoluto, e não relativo. Mas se algo fosse absoluto, nem tudo seria relativo. $E$, se nem tudo é relativo, quem pode e deve decidir sobre o que é e o que não é relativo? Assim, Connor mostra que o valor não pode ser absolutamente contingente e, de certa forma, nos impele a pensar que essa absolutização do relativo, ou a universalização do contingente, é uma tentativa de escapar do poder gravitacional do valor.

Do ponto de vista da teatralidade, também parece haver, da parte do comportamento justiceiro, uma necessidade de identificação absoluta entre real e ficcional. Tem sido cada vez mais frequente exigir que a representação do sujeito minoritário seja desempenhada exclusivamente por esse sujeito, ou seja, apenas uma travesti deveria representar uma travesti; apenas uma mulher trans deveria representar uma mulher trans. Essa reivindicação sugere um retorno às estéticas anteriores às do século XX, podendo mesmo estar sugerindo uma espécie de vitória da ambição naturalista: em cena, finalmente, o real; no lugar da estética, a militância, no sentido mais estreito do termo.

\section{Considerações finais}

É inegável que as relações entre cena teatral e minoritarismo precisam ser reconfiguradas. As argumentações que defendem a liberdade de expressão artística parecem plenamente justificadas: em termos de história do Brasil, ainda na década de 1980, havia censores aos quais o espetáculo deveria ser apresentado previamente; somente após sua liberação, o espetáculo poderia entrar em cartaz. Apresentando a questão sob esse aspecto, é inegável que a maioria da população e das/dos artistas não deseja a volta da censura.

Também as argumentações de certos grupos sociais de que estão fartos de ser apresentados em cena de modo reducionista, caricatural e, finalmente, preconceituoso são plenamente justificadas.

Seria incoerente apresentarmos aqui uma proposta de uma nova estética teatral já reconfigurada em sua relação com o que chamamos de minoritarismo. Essa reconfiguração será realizada no próprio dinamismo desse campo e, certamente, caso ela efetivamente venha a se constituir, não possuirá autoria.

\footnotetext{
${ }^{16}$ Em 2017, li uma postagem em mídia social de estudante de nível universitário que reclamava de ser vítima de grosserias de outras/os estudantes. Ao que outra pessoa, também estudante de nível universitário comentou, dizendo que a pessoa que cometeu o ato poderia não considerar como grosseria o que havia feito, justificando assim a possibilidade de atitudes grosseiras; ao emitir esse comentário, a/o autor/a fundamentou-se justamente na relatividade do real, sem perceber que, com isso, abre-se a possibilidade de justificar qualquer tipo de agressão verbal, já que o emissor pode dizer: isso não é grosseria para mim.
} 
Por isso, apresentamos aqui, a título de considerações finais, o que acreditamos ser os princípios/procedimentos teóricos que deveriam sustentar o andamento da referida reconfiguração.

A cultura da crítica é o primeiro e, de todos, o mais valioso desses procedimentos. A cultura aqui deve ser compreendida no sentido de cultivo, técnica que dialoga com a temporalidade e a localidade relacionadas ao que é cultivado. $O$ cultivo constitui-se a partir de um diálogo com essas duas instâncias e firma-se na longa duração. Não se obtém uma boa colheita se, por exemplo, a terra não for permanentemente cuidada. A crítica deve ser compreendida enquanto modo inquietante de interação com o mundo. Trata-se de uma discussão constante da própria condição de possibilidade dos sentidos de mundo, que não podem ser exclusivamente derivados de um princípio, seja ele qual for. A cultura da crítica exige o questionamento da autonomia do sujeito em sua capacidade de significar o mundo e simultaneamente o reconhecimento de sua capacidade de transformar os sentidos de mundo. $O$ sentido do real não é nem uma atribuição do sujeito ao mundo, nem uma determinação estabelecida pela situação do sujeito no mundo. O cultivo da crítica é o movimento ininterrupto de questionamento dos fundamentos da produção de sentido do mundo. Evidentemente, todo dogmatismo, de qualquer tipo que seja, só pode contribuir para a interrupção do movimento de questionamento. Nesse sentido, as ideologias - entendidas aqui enquanto práticas discursivas que, em vez de criar possibilidades de questionamento de sentido, procuram naturalizar o sentido do mundo - devem ser combatidas. É preciso, portanto e apenas a título de exemplo, se posicionar radicalmente contra a ideologia de gênero. Entenda-se aqui ideologia de gênero como práticas discursivas que naturalizam os sentidos de gênero (gender) em vez de questionar os fundamentos da produção de seus sentidos no mundo. Assim, as instituições de educação e os planos, constantemente atualizados, que vêm servindo de parâmetros para ações de educação são lugares e instrumentos próprios para as discussões de gênero e para o combate à ideologia de gênero. As discussões sobre gênero, portanto, vêm justamente combatendo a ideologia de gênero naturalizada em nosso mundo, criando possibilidades de sentido para o que seja mulher, homem, feminilidade, masculinidade etc. Portanto, aquelas e aqueles que se dizem em geral contra a ideologia de gênero vêm tentando estabelecer baluartes daquilo que deve ser efetivamente chamado de ideologia de gênero. $O$ teatro, localizado nas instâncias do imaginário, é um lugar privilegiado para a visualização de novos sentidos do que seja, por exemplo, gênero (gender) e de como pode ser discutida essa questão em termos cênicos.

O segundo princípio seria o da diferenciação entre identidade minoritária e vítima. Há que fazer um esforço para que as lutas de conquistas de direitos de grupos considerados minoritários se diferenciem de julgamentos de atos que atentem contra os direitos humanos. Inegavelmente indivíduos de grupos minoritários são cotidianamente agredidos verbal e fisicamente, o que, no entanto, não os deve transformar eternamente em vítimas. Parece haver uma idealização da identidade minoritária, que estaria isenta de qualquer característica opressora, como se fosse possível haver algum indivíduo absolutamente impermeável a qualquer tipo de traço opressor. Aqui 
parece haver de novo um retorno a identidades naturalizadas e estáveis; mais ainda, um retorno a identidades puras, situadas numa espécie de aquém ou de além das situações de poder do mundo atual.

Nesse sentido, creio que a pergunta sobre se devemos banir da cena ou impedir de vir à cena situação humilhante para grupos minoritários deve ser respondida, considerando sua complexidade. Não nos parece cabível impedir de vir à cena esse tipo de situação. Não porque a cena teatral deva ser autônoma, mas porque a cena teatral deve ser consteladora e não justiceira. Esse tipo de cena, contudo, não nos parece recomendável para a contemporaneidade, porque esse tipo de exibição de situação humilhante reitera o lugar de vítima dos grupos minoritários, os reduzindo ao papel de vítima, em vez de exibir sua complexidade, que abarca toda uma constelação de identidades. Nesse sentido, a exibição de situações degradantes e humilhantes em relação a esses grupos minoritários termina por clamar a presença das/ dos militantes justiceiras/os, que frequentemente vêm confundindo justiça com justiçamento, acreditando que a eliminação sumária do suposto opressor extirpará a opressão. Apesar do inestimável valor da obra de Plínio Marcos, ${ }^{17}$ os espetáculos atuais que partem de seus textos frequentemente enfatizam o papel de vítima dos grupos minoritários, contribuindo para uma reiteração dos estereótipos em torno de lésbicas, travestis, homens homossexuais, prostitutas e todo tipo de população dita minoritária. ${ }^{18}$

Não estamos defendendo aqui a ideia de que toda e qualquer obra tenha direito de existência. Há que diferenciar a liberdade de expressão do discurso de ódio. $O$ discurso de ódio não deve ser autorizado pelo Estado, sob pena de implementar o vale-tudo relativista: todas e todos têm o direito de expressar suas ideias sejam elas quais forem. Porém, o ódio deve ser combatido não com sua simples supressão, pois ele não cessará de retornar; todo espectro retorna; todo recalcado retorna e assim sobrevive. O ódio deve ser combatido por meio de sua localização dentro de um sistema crítico de valores específicos, que não cessa de se deslocar. O ódio carece de espírito crítico, desejando impor seus valores a partir de perspectivas dogmáticas. Cada vez que Estado se ausenta e que as instituições que o representam permitem em seus espaços opiniões que defendem, por exemplo, a inexistência do extermínio de judeus, ciganos, LGBTs e outras populações por parte do regime nazista alemão; a ideia de imigração negra em oposição à de tráfico de mão de obra escrava negra; a ideia de que a homossexualidade é uma doença passível de cura, o Estado referenda o ódio e a irracionalidade.

O terceiro princípio é o da compreensão da identidade enquanto constelação. Recentemente, encenamos o espetáculo Always (K)new. Ao ser questionada sobre como se autoidentificaria dentro do universo LGBT, Laura Dias respondeu (2017):

\footnotetext{
7 Há que registrar aqui a recente publicação da obra teatral completa de Plínio Marcos pela Funarte. Os seis volumes foram cuidadosamente organizados, permitindo o acesso a documentação visual e textual de grande importância para o estudo da obra do dramaturgo.

18 É importante citar aqui a obra crítica de Albuquerque (2004). Apesar de considerar que o autor às vezes carece de uma visão histórica que compreenda o papel da obra de Plínio Marcos no contexto do teatro brasileiro, exigindo da obra e do autor características que a situação teatral e política do Brasil não permitiriam, Albuquerque aponta para o reforço dos estereótipos da população LGBT e para a dificuldade que artistas LGBTs tinham de aparecer enquanto autores, atrizes, atores etc., o que não ocorre com Plínio Marcos, autor de orientação heterossexual.
} 
O que eu gosto mais é transfeminina, acho que vem do próprio inglês transfeminine porque acho que reflete melhor o que eu sou, porque eu nunca fui muito confortável com o termo mulher para se aplicar a mim. Eu me afirmo como mulher muitas vezes e eu entendo que a minha identidade, ela é meio constelar, ela está constelando mulher, viado, transfeminina, sabe? Porque também não tem como eu - eu sei que hoje eu me coloco como mulher na sociedade, eu sou lida como mulher a maior parte do tempo, mas eu não, eu não acho que seja fidedigno exatamente eu me conter nessa palavra, eu me resumir na palavra mulher. Porque ela não - porque a gente sabe o que significa mulher na linguagem corrente e isso não é necessariamente algo que me contempla.

Assim, a identidade pode ser pensada como uma região, na qual certos corpos, por meio de linhas imaginárias, criam uma imagem, em vez de se estabelecer como um determinado corpo que, a partir de certas propriedades, estabelece relações com outros corpos.

Nesse sentido, é importante na atual conjuntura histórica e política, tanto em termos de Brasil quanto em termos de conjuntura mundializada, formar artistas consteladoras/es que, em vez de excluir e banir do real tudo aquilo que é considerado nocivo, possam reconfigurar e, portanto, criar, a partir dos corpos/estrelas já existentes, novas constelações, ou seja, linhas imaginárias que relacionem esses corpos e produzam novas figuras. As/Os artistas consteladoras/es estão firmadas/os pelo princípio da incorporação, reconhecendo o lugar de cada corpo em sua devida constelação e simultaneamente reconhecendo o que é próprio de cada corpo. Mais ainda, as/os artistas consteladoras/es reconhecem que a identidade não é um corpo isolado e autônomo, mas sim uma região na qual brilham e se movem vários corpos que a constituem, produzindo figuras que só podem ser visíveis pela força da imaginação.

\section{Referências}

ALBUQUERQUE, Severino J. Tentative transgressions: homosexuality, Aids and the theater in Brazil. Madison: University of Wisconsin Press, 2004.

BUTLER, Judith. Problemas de gênero: feminismo e subversão da identidade. Rio de Janeiro: Civilização Brasileira, 2015.

BUTLER, Judith. Gender trouble. Feminism and the subversion of identity. New York; London: Routledge, 2008.

CONNOR, Steven. Teoria e valor cultural. São Paulo: Edições Loyola, 1994.

COSTA E SILVA, Álvaro. Robôs do ódio dominam as redes sociais. Folha de S. Paulo, São Paulo, 24 out. 2017. Disponível em http://www1.folha.uol.com.br/colunas/alvaro-costa-e-silva/2017/10/1929571-robos-do-odio-dominam-asredes-sociais.shtml. Acesso em: 25 out. 2017.

DIAS, Laura. Entrevista concedida ao prof. Alberto Ferreira da Rocha Junior/Alberto Tibaji (UFSJ) e ao prof. Robert Moser (University of Georgia, EUA), 2017. 
FIORATTI, Gustavo. Antes de cancelar peça acusada de racismo, mostra propôs troca a autor. Folha de S. Paulo, São Paulo, 19 fev. 2016. Disponível em http://www1. folha.uol.com.br/ilustrada/2016/02/1740795-mitsp-propos-trocar-peca-acusada-de-racismo-antesde-cancelar-realizacao.shtml. Acesso em: 25 out. 2017.

MUIR, Hugh. Slavery exhibition featuring black actors chained in cages shut down. The Guardian, London, 23 set. 2014. Disponível em https://www.theguardian.com/ culture/2014/sep/24/slavery-exhibition-black-actors-cages-shut-down. Acesso em: 25 out. 2017.

PONDÉ, Luiz Felipe. Jesus transexual qualquer um faz. Que tal uma peça de Maomé transexual? Folha de S. Paulo, São Paulo, 23 out. 2017. Disponível em http://www1. folha.uol.com.br/colunas/luizfelipeponde/2017/10/1929263-coragem-de-salao. shtml. Acesso em: 23 out. 2017.

SEDGWICK, Eve Kosofsky. Epistemology of the closet. Berkeley; Los Angeles; London: University of California Press, 2008.

SPARGO, Tamsin. Foucault e a teoria queer. Seguido de Ágape e êxtase: orientações pós-seculares. Belo Horizonte: Autêntica, 2017.

TIBAJI, Alberto. Autonomia: um momento da história da arte. ArtCultura, Uberlândia, v. 1, n. 2, p. 76-85, 2000.

VENTURA, Roberto. Estilo tropical: história cultural e polêmicas literárias no Brasil. São Paulo: Companhia das Letras, 1991.

Recebido em: 06/08/2018

Aprovado em: 29/01/2019 